\title{
Agents and rough sets
}

\author{
Germano Resconi \\ Catholic University, Via Trieste 17 \\ Brescia \\ Italy \\ Chris Hinde \\ Department of Computer Science, \\ Loughborough University,Loughborough, \\ Leicestershire LE11 3TU \\ United Kingdom \\ Received 15 December 2012 \\ Accepted 8 July 2013
}

\begin{abstract}
Rough set theory gives approximation models of complex knowledge structure. Agents are not present in the definition of the rough sets. Now we will show that a set of conflicting agents or active set can be used to model inconsistent decision in rough set theory. Agent models give us the logic structure of the rough set theory. We think that vagueness in rough sets can be evaluated by a true, false complex structure of agents and classes. With the active set the logic evaluation of a rough set is a structured set of classical logic values as true and false. We show that many valued logic and lattices modelled by active sets are used to create class operations in rough sets. By active sets, relations in rough sets are modelled by matrices of classical logic values. This clarifies the deeper meaning of the decision rules in rough sets.
\end{abstract}

Keywords: Agents, active sets, rough sets, conflict, inconsistency.

\section{Introduction}

This paper begins with a short introduction to active set theory. After that we show that it is possible to represent evidence theory as a simple case of the rough set and active set of agents. Then we extend the agent interpretation of evidence theory to rough set classes. We also introduce the relation between rough set classes and lattice logic theory. In the end we show that the dominance - based rough set approach (DRSA) can be modelled by agents to give a more transparent meaning to rough sets and decision rules.

\section{Short introduction to active sets}

In the paper "Belief merging and voting" ${ }^{13-15}$ we found that in the voting model there are several conflicting demands/preferences and we are looking for a collective compromise. Voting is concerned with the aggregation of individual preferences in order to select a collectively preferred alternative. This problem is extensively studied by social choice theory ${ }^{38,39,40}$. Probably the most famous method for the aggregation of preferences is the one proposed in the 18th century by the Marquis de Condorcet ${ }^{41}$. Given a set of individual preferences, we compare each of the alternatives in pairs. For each pair we determine the winner by majority voting, and the final collective ordering is obtained by a combination of all partial results. Unfortunately, this method led to the first aggregation problem, known as the Condorcet paradox: the pair wise majority rule can lead to cycles in the collective ordering. In other words, this ordering cannot be used to select an overall preferred candidate.

In ${ }^{42}$ given a fuzzy set defined in a space $\mathrm{X}$, let $\mathrm{P}$ be a representative population of persons. For a given $\mathrm{x}$ that belongs to $\mathrm{X}$ each member of $\mathrm{P}$ is asked to accept or reject $\mathrm{X}$ as satisfying the set condition. A binary decision must be made. Now for a group of 10 persons, as in Equation 1, the voting pattern could then be

$X=\{a, b, c, d, e, f, g, h, i, j\}$ 
as in Equation 2,

$$
X=\left[\begin{array}{cccccccccc}
1 & 2 & 3 & 4 & 5 & 6 & 7 & 8 & 9 & 10 \\
a & a & a & a & a & a & a & a & a & a \\
& & & b & b & b & b & b & & b \\
& & & c & & c & & c & & c \\
& & & d & & d & & & &
\end{array}\right]
$$

resulting in the fuzzy set shown in Equation 3,

$$
f=\{1.0|a+0.7| b+0.5|c+0.2| d\}
$$

Now in the voting pattern we allow repetitions of the elements in X. To agree to the fuzzy set definition, we can order the elements so that the highest count is to the left and the counts decrease towards the right, see Figure 1.

$$
\left[\begin{array}{rrrrrrrrrr}
1 & 2 & 3 & 4 & 5 & 6 & 7 & 8 & 9 & 10 \\
a & a & a & a & a & a & a & a & a & a \\
b & b & b & b & b & b & b & & & \\
c & c & c & c & & & & & & \\
d & d & & & & & & & &
\end{array}\right]
$$

Figure 1. Showing the elements ordered.

If the elements are ordered and we grant that any voter who votes for $b$ will vote for a then we get a unique representation $13,14,15$. The new freedom for which we can have many voting patterns opens the door to introduce not only $\mathrm{min} / \mathrm{max}$ logic rules but many more logic operations. Now this extension is denoted Active set model of agents where we fuse the classical vote model with all other types of uncertainty and logics.

\subsection{Properties and definition of the active set}

An active set is a unifying space being able to act as a "bridge" for transferring information, ideas and results between distinct types of uncertainties and different types of applications. An active set is a set of agents who independently deliver true or false values for a given proposition. An active set is not a simple vector of logic values for different propositions, the results are a vector but the set is not. The difference between an ordinary set and active set is that the ordinary set has passive elements with values of the attributes defined by an external agent, in the active set any element is an agent that internally defines the value of a given attribute for a passive element. Agents in the active set with a special criteria gives the logic value for the same attribute. So agents in many cases are in a logic conflict and this generate semantic uncertainty on the logic evaluation. Criteria and agents are the two variables by which we give different logic values to the same attribute or proposition. Active sets is beyond modal logic. In fact given a proposition in modal logic we can evaluate the proposition only when we know the worlds where the proposition is locate. When we evaluate one proposition in one world we cannot evaluate the same proposition in another world. Now in epistemic logic any world is an agent that know that the proposition is true or false. Now the active set is a set of agents as in the epistemic logic but the difference with modal logic is that all the agents (worlds) are not separate but are joined in the evaluation of the given proposition. In active set for one agent and one criterion we have one logic value but for many agents and criteria the evaluation is not true and false but is a matrix of true and false. This matrix is not only a logic evaluation as in the modal logic but give us the conflicting structure of the active set evaluation. Matrix agent is the vector subspace of the true false agent multi dimension space. Operations among active set include operations in the traditional set, fuzzy sets and rough set as special cases. New logic operations are possible as fuzzy gate operations and more complex operations as conflicting solving, consensus operations, syntactic inconsistency, semantic inconsistency and knowledge integration. In the space of the agents evaluations active set open new possibility and new models for the logic. Formally equation 4 shows a structure for $\Omega$.

$$
\begin{aligned}
& \Omega(p)=\left(\begin{array}{cccc}
\text { Agent } & 1 & 2 & 3 \\
\text { Logic value } & \text { true } & \text { true } & \text { true }
\end{array}\right), \\
& \left(\begin{array}{cccc}
\text { Agent } & 1 & 2 & 3 \\
\text { Logic value true } & \text { true } & \text { false }
\end{array}\right), \ldots . . \\
& \text {........ }\left(\begin{array}{cccc}
\text { Agent } & 1 & 2 & 3 \\
\text { Logic value } & \text { false } & \text { false } & \text { false }
\end{array}\right)
\end{aligned}
$$

In a more formal way we have in Equation 5.

$$
S S(p)=\left\{\begin{array}{l}
A, \Omega(p) \mid \\
A=\text { set of agents, } \\
\Omega(p)=\text { power set } 2^{A} \text { of the evaluations }
\end{array}\right\}(5)
$$

Given the proposition $\mathrm{p}$, we denote as Criteria $\mathrm{C}$ one of the possible evaluations $p$ in the set $\Omega(p)$. For example with three agents we have eight criteria to 
evaluate the proposition itself so we can write equation 6 .

$$
\begin{aligned}
& \Omega\left(p, C_{1}\right)=\left(\begin{array}{cccc}
\text { Agent } & 1 & 2 & 3 \\
\text { Logic value } & \text { true } & \text { true } & \text { true }
\end{array}\right), \ldots, \\
& \Omega\left(p, C_{8}\right)=\left(\begin{array}{cccc}
\text { Agent } & 1 & 2 & 3 \\
\text { Logic value } & \text { false } & \text { false } & \text { false }
\end{array}\right)(6)
\end{aligned}
$$

We remark that the set of Criteria is a lattice. The agent set $\mathrm{A}$ is an ordinary set with normal intersection union and complementary operator. For the logic evaluation we have three different operations.

1) Operation among criteria for the same proposition. Because we have the same proposition with two different criteria, we cannot compose the logic values that are heterogeneous. So we have the rule in Equation 7.

$C_{i} \oplus C_{j}=\left(\begin{array}{ccccc}\text { Agent } & 1 & 2 & \ldots & n \\ C_{i} & v_{1,1} & v_{1,2} & \ldots & v_{1, n} \\ C_{j} & v_{2,1} & v_{2,2} & \ldots & v_{2, n}\end{array}\right)$ (7)

So we increase the dimension of the space of the evaluation. For example given ten agents and two criteria we have in Equation 8.

$\Omega\left(p, C_{i}, C_{j}\right)=\left(\begin{array}{cccccc}\text { Agents } & 1 & 2 & 3 & 4 & 5 \\ p, C_{i} & f & f & t & t & f \\ p, C_{j} & t & t & f & t & f\end{array}\right)$

2) For two different propositions $p$ and $q$ we have the composition rule for the active set shown in Equation 9 with disjunction shown in Equation 10.

$\Omega(p \wedge q, C)=\left(\begin{array}{cccc}\text { Agents } & 1 & \ldots & n \\ p, C & v_{1, p} & \ldots & v_{n, p}\end{array}\right) \wedge\left(\begin{array}{cccc}\text { Agents } & 1 & \ldots & n \\ q, C & v_{1, p} & \ldots & v_{n, p}\end{array}\right)$

$=\left(\begin{array}{ccccc}\text { Agents } & 1 & 2 & \cdots & n \\ p, q, C & v_{1, p} \wedge v_{1, q} & v_{2, p^{\wedge}} \wedge v_{2, q} & \cdots & v_{n, p} \wedge v_{n, q}\end{array}\right)$

$$
\begin{aligned}
& \Omega(p \vee q, C)=\left(\begin{array}{cccc}
\text { Agents } & 1 & \ldots & n \\
p, C & v_{1, p} & \ldots & v_{n, p}
\end{array}\right) \vee\left(\begin{array}{cccc}
\text { Agents } & 1 & \ldots & n \\
q, C & v_{1, p} & \ldots & v_{n, p}
\end{array}\right) \\
& =\left(\begin{array}{ccccc}
\text { Agents } & 1 & 2 & \ldots & n \\
p, q, C & v_{1, p} \vee v_{1, q} & v_{2, p} \vee v_{2, q} & \ldots & v_{n, p} \vee v_{n, q}
\end{array}\right)
\end{aligned}
$$

The negation operator is shown in Equation 11.

$\Omega(-p)=$

$=\left(\begin{array}{cccc}\text { Agents } & 1 & \ldots & n \\ \text { value } & \alpha_{1}\left(\neg v_{1}\right)+\left(1-\alpha_{1}\right)\left(v_{1}\right) & \ldots & \alpha_{n}\left(\neg v_{n}\right)+\left(1-\alpha_{n}\right)\left(v_{n}\right)\end{array}\right)(11)$

3) Aggregation rule for active set

Given an active set we associate to any active set evaluation a number by an aggregation function that can be linear or non linear. For the linear case the aggregation can be simple aggregation or weighted aggregation. For example for simple linear aggregation rule we have the aggregation rule shown in Figure 2.

$$
\begin{aligned}
& \text { for } \Omega\left(p, C_{1}\right)=\left(\begin{array}{cccc}
\text { Agent } & 1 & 2 & 3 \\
\text { Logic value } & \text { true } & \text { true } & \text { true }
\end{array}\right), \\
& \left.\left.\left.Q=\mu\left(p, C_{1}\right)=\frac{1}{3} \mid \text { true }\right\rangle+\frac{1}{6} \mid \text { true }\right\rangle+\frac{1}{3} \mid \text { true }\right\rangle \\
& =\frac{1}{3}+\frac{1}{6}+\frac{1}{3}=\frac{5}{6}
\end{aligned}
$$

Figure 2. The simple linear aggregation rule.

Where $\mathrm{Q}$ is the linear superposition of the logic value for the active set. Resconi ${ }^{1-8}$, Hinde ${ }^{16-24}$.

\subsection{Active set as an extension of epistemic logic}

Epistemic logic is the logic, which formalizes knowledge of agents. Among many applications it is used in game theories and economic behaviour in databases and in verifying cryptographic protocols Shared knowledge, common knowledge. Epistemic logic is also known as the logic of knowledge, it deals with modalities, which are not part of traditional logic and which modify the meaning of a proposition. For instance such a modality is the knowledge modality: "agent Alice knows that ...", written $\mathrm{K}_{\text {Alice. }}$ There is one knowledge modality $\mathrm{K}_{\mathrm{i}}$ for each agent $\mathrm{i}$, so when there are $\mathrm{n}$ agents, there are $\mathrm{n}$ knowledge modalities. From the $\mathrm{K}_{\mathrm{i}}$ 's, one can build two new modalities, namely a modality Eg of shared knowledge, which modifies a proposition $\mathrm{p}$ into a proposition $\mathrm{Eg}(\mathrm{p})$ which means that "everyone in the group g knows $\mathrm{p}$ " and a modality $\mathrm{Cg}$ of common knowledge. $\mathrm{Cg}(\mathrm{p})$ would say " $\mathrm{p}$ is known 
to everybody in the group g" in a very strong sense since knowledge about $\mathrm{p}$ is known at every level of knowledge. Slightly more precisely, if $g$ is the group of agents and $\mathrm{p}$ is a proposition, $\operatorname{Eg}(\mathrm{p})$ is the conjunction over the i $2 \mathrm{~g}$ of the $\mathrm{K}_{\mathrm{i}}(\mathrm{p})$ and $\mathrm{Cg}(\mathrm{p})$ means something like "everybody knows $\mathrm{p}$ and everybody knows that everybody knows $\mathrm{p}$ and ... and everybody knows that everybody knows that everybody knows ...that everybody knows p..." This infinite conjunction is handled by making $\mathrm{Cg}(\mathrm{p})$ a fix point. A typical example of common knowledge is traffic regulation. When, as a car driver, you enter an intersection you know that the person on your left will let you go, moreover you know that she knows that you have the right to go and you are sure (you know) that she will not go because she knows that you know that she knows that you have the right to go etc. Actually you pass an intersection with a car on your left, because there is a common knowledge between you as a driver and the driver of the other car on the rule of priority. But those who travel have experienced the variability of the common knowledge. Take a stop sign. In Europe it means that the person which has a stop sign will let the other to pass the intersection. In some countries, the stop sign is just a decoration of intersections. In the USA, the common knowledge is different since there are intersections of two crossing roads with four stop signs and this has puzzled more than one European. One main goal of epistemic logic is to handle properly those concepts of knowledge. Any epistemic logic can be represented by active set of agents, which shared knowledge as common knowledge. So we have the Epistemic logic evaluation by active set formal description

$$
K_{\alpha}(p)=\left(\begin{array}{cccc}
\text { Agent } & 1 & 2 & 3 \\
\text { Logic value } & \text { true } & \text { false } & \text { true }
\end{array}\right)
$$

Where $\mathrm{p}$ is the proposition that we want to evaluate and $\alpha$ is the agent for which $p$ is true or false that is known.

\subsection{Fuzzy set by active set}

The probability calculus does not incorporate explicitly the concepts of irrationality or agent's state of logic conflict. It misses structural information at the level of individual objects, but preserves global information at the level of a set of objects. Given a dice the probability theory studies frequencies of the different faces $E=\{e\}$ as independent (elementary) events. This set of elementary events $\mathrm{E}$ has no structure. It is only required that elements of $\mathrm{E}$ are mutually exclusive and complete, that is no other alternative is possible. The order of its elements is irrelevant to probabilities of each element of E. No irrationality or conflict is allowed in this definition relative to mutual exclusion. The classical probability calculus does not provide a mechanism for modelling uncertainty when agents communicate (collaborates or conflict). Below we present the important properties of sets of conflicting agents at one dimension Let $\Omega(\mathrm{x})$ the active set for the proposition $\mathrm{x}$ and $|\Omega(\mathrm{x})|$ be the numbers of agents for which proposition $\mathrm{x}$ is true we have

Given two propositions $\mathrm{a}$ and $\mathrm{b}$ when

$$
\begin{aligned}
& \text { If }|\Omega(a)|<|\Omega(b)| \text { then } p=a \text { and } q=b \\
& \text { If }|\Omega(b)|<|\Omega(a)| \text { then } p=b \text { and } q=a
\end{aligned}
$$

So we order the propositions from the proposition with less number of true value to the proposition with maximum values of true values.

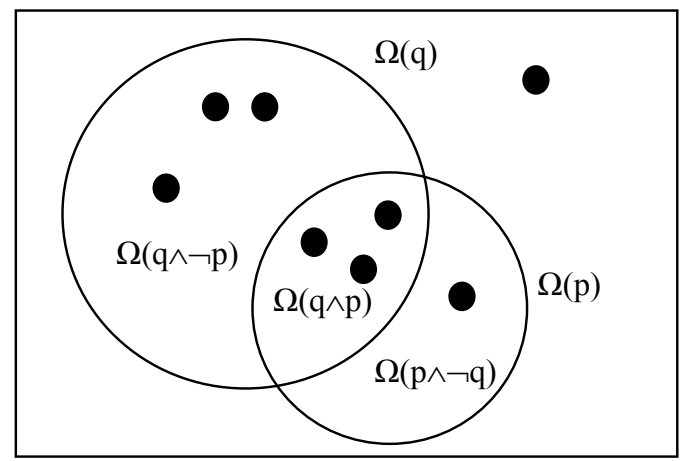

Figure 3 Sets of agents and their intersections

$$
\begin{aligned}
& \Omega(p)=\left(\begin{array}{lllllllll}
\text { Agents } & 1 & 2 & 3 & 4 & 5 & 6 & 7 & 8 \\
\text { values } & f & f & t & t & t & t & f & f
\end{array}\right) \\
& \Omega(q)=\left(\begin{array}{lllllllll}
\text { Agents } & 1 & 2 & 3 & 4 & 5 & 6 & 7 & 8 \\
\text { values } & f & t & t & f & t & t & f & t
\end{array}\right) \\
& |\Omega(p)|=4,|\Omega(q)|=5
\end{aligned}
$$


We have

$$
\begin{aligned}
& \Omega(p \wedge q)=\left(\begin{array}{lllllllll}
\text { Agents } & 1 & 2 & 3 & 4 & 5 & 6 & 7 & 8 \\
\text { values } & f & f & t & f & t & t & f & f
\end{array}\right) \\
& \Omega(p \vee q)=\left(\begin{array}{lllllllll}
\text { Agents } & 1 & 2 & 3 & 4 & 5 & 6 & 7 & 8 \\
\text { values } & f & t & t & t & t & t & f & t,
\end{array}\right) \\
& |\Omega(p \wedge q)=3|,|\Omega(p \vee q)=6|
\end{aligned}
$$

Now we know

$q \vee(p \wedge \neg q)=(q \vee p) \wedge(q \vee \neg q)=q \vee p$

$p \wedge \neg(p \wedge \neg q)=p \wedge(\neg p \vee q)=(p \wedge \neg p) \vee p \wedge q=p \wedge q$

But because when $q$ is false and $p$ is true we adjoin at $q$ one logic value true to obtain $p$ or $q$. So when we repeat this process many times for any agent we have that at the number of true values for $\mathrm{q}$ we must adjoin other true values for which $q$ is false but $p$ is true. In conclusion we have

$$
\begin{aligned}
& |\Omega(p \vee q)|=|\Omega(q)|+|\Omega(\neg q \wedge p)| \\
& =\max (|\Omega(q)|,|\Omega(p)|+|\Omega(\neg q \wedge p)|
\end{aligned}
$$

For and operation we have that when $q$ is false and $p$ is true we eliminate one element for which $p$ is true. In conclusion when we repeat this as necessary

$$
\begin{aligned}
& |\Omega(p \wedge q)|=|\Omega(p)|-|\Omega(\neg q \wedge p)|= \\
& \min (|\Omega(q)|,|\Omega(p)|+|\Omega(\neg q \wedge p)|
\end{aligned}
$$

In conclusion in the active set we can found again the Zadeh rule when $\mathrm{p}$ and not $\mathrm{q}$ is always false

$$
\begin{aligned}
& |\Omega(p \wedge q)|=\min (|\Omega(q)|,|\Omega(p)| \\
& \Omega(p \vee q) \mid=\max (|\Omega(q)|,|\Omega(p)|
\end{aligned}
$$

So when the agents for which $\mathrm{p}$ is true are also the agents for which $\mathrm{q}$ is true. Figure 4 shows it graphically.

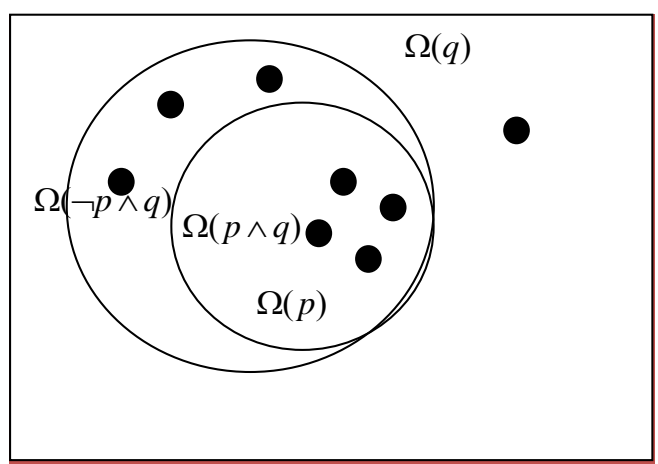

Figure 4. Graphic representation of active set of agents where one is included in the others. The AND rule is the same of the Zadeh min rule.

\section{Evidence theory and agents}

In this section we give a model of the evidence theory by rough set theory and agent. In fact given the table

\begin{tabular}{|l|l|l|l|l|}
\hline Students & math & Ph & Lit & Overall \\
\hline S1 & good & bad & bad & bad \\
\hline S2 & bad & good & bad & bad \\
\hline S3 & good & bad & good & bad \\
\hline S4 & good & bad & good & good \\
\hline S5 & good & good & good & good \\
\hline S6 & bad & good & good & bad \\
\hline S7 & good & bad & bad & good \\
\hline S8 & bad & bad & bad & bad \\
\hline
\end{tabular}

where bad and good are classes in rough set theory and bad is negation of good

bad $=\neg$ good, the rough set evaluation of the student $\mathrm{S} 1$ can be represented by the active set in Figure 5,

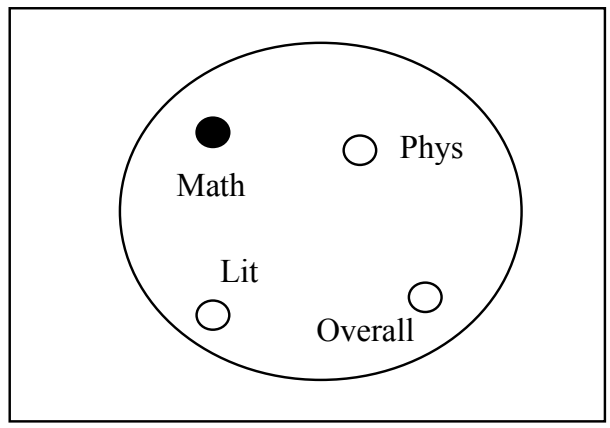

Figure 5. Graphic representation of agents whose value is good (black) or bad (white). 
where black is good and white is bad. Maths, Phys, Literature and Overall are four agents in the active set theory or criteria in the rough set theory. For the student S1 the value of the active set is given by this complex structure of true and false, as shown in Equation 13.

$V\left(\right.$ Student $_{1} \in\left(\right.$ professor $_{i}$, good $)=K_{i, j}^{1}$

$=\left(\begin{array}{ccccc}\text { active set } & \text { Math } & \text { Phys } & \text { Lite } & \text { Overall } \\ \text { good } & \text { true } & \text { false } & \text { false } & \text { false }\end{array}\right)\left[\begin{array}{c}\text { number true } \\ 1\end{array}\right]$

$S 1=\{$ good $=$ math $\}$

In S1 good is true only for the maths professor.

The number of possible evaluations is the power set of the possible agents. So for four agents the number of the evaluations is $2^{4}=16$.

We define the basic assignment probability as proportional to the number of true values in the active set. Now we have 8 evaluations for the 8 students. For the student S1 good is true only once, for the student S2 good is true only once, for the student S3 good is true twice and for the student S8 good is true zero times. All the other vectors of the power set of the 4 agents have basic probability equal to zero. Now the total number of true values for the students is

$\mathrm{T}=1+1+2+3+4+2+2+0=15$

So we have the values of the basic assignment probability

$$
\begin{aligned}
& m(S 1)=\frac{1}{15}, m(S 2)=\frac{1}{15}, m(S 3)=\frac{2}{15}, m(S 4)=\frac{3}{15} \\
& m(S 5)=\frac{4}{15}, m(S 6)=\frac{2}{15}, m(S 7)=\frac{2}{15}, m(S 8)=0 \\
& \text { for the other } 8 \text { possible evaluation } m=0
\end{aligned}
$$

With the basic assignment probability we can compute the Belief and Plausibility measures to give a set of true values for the four agents.

For example given the active set in Equation 15

$$
S 4=\left(\begin{array}{cccc}
\text { active set } & \text { Math } & \text { Phys Lit } & \text { Overall } \\
\text { good } & \text { true } & \text { false true } & \text { true }
\end{array}\right)
$$

The sets included in S4 are in Equation 16

$$
\begin{aligned}
\text { S7 } & =\left(\begin{array}{ccccc}
\text { active set } & \text { Math } & \text { Phys } & \text { Lit } & \text { Overall } \\
\text { good } & \text { true } & \text { false } & \text { false } & \text { true }
\end{array}\right) \\
S 1 & =\left(\begin{array}{ccccc}
\text { active set } & \text { Math } & \text { Phys } & \text { Lit } & \text { Overall } \\
\text { good } & \text { true } & \text { false } & \text { false } & \text { false }
\end{array}\right) \\
\text { S3 } & =\left(\begin{array}{ccccc}
\text { active set } & \text { Math } & \text { Phys } & \text { Lit } & \text { Overall } \\
\text { good } & \text { true } & \text { false } & \text { true } & \text { false }
\end{array}\right)
\end{aligned}
$$

The Belief measure is

$$
\operatorname{Bel}(S 4)=m(S 1)+m(S 3)+m(S 4)+m(S 7)=\frac{8}{15}
$$

The Plausibility measure of S4 is

$$
\begin{aligned}
& P l(S 4)=m(S 1)+m(S 3)+m(S 4)+m(S 7) \\
& +m(S 6)+m(S 5)=\frac{14}{15}
\end{aligned}
$$

Figure 6 shows graphically the way we have the sets included in S4 and also the set S4 itself. Any sets have four agents with true or false evaluation.

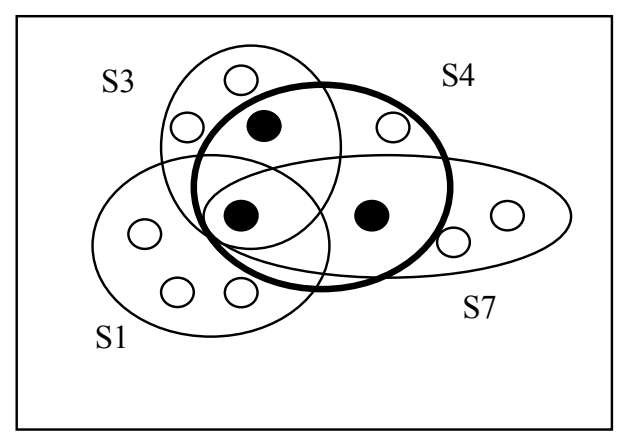

Figure 6. The agents which value is good are all included in S4 for any active set S3, S1, S7. So the Believe measure of $\mathrm{S} 4$ is the sum of the basic assignment of S4, S1, S3, S7.

For the Plausible measure we have the sets S5 and $\mathrm{S} 6$ that are not included in S4 but have common elements can be seen in the Figure 7. 


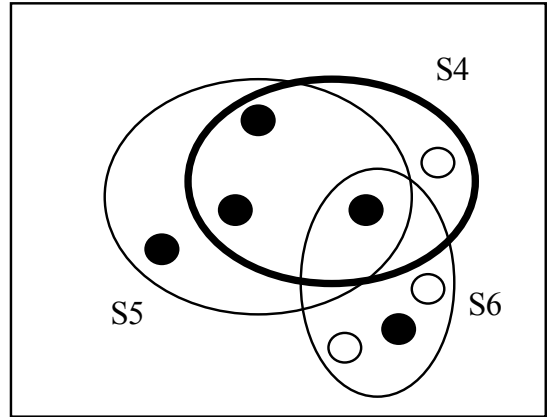

Figure 7. The agents for which the value is good are not all included in S4 for any active set S5, S6. But S6 and S5 has "good" valued inside S4 and another good value outside. The active set S6, S5 cannot included in S4 but has common elements with S4. So we can compute the Plausible measure for S4 by S5, S6 and S4 itself.

\section{Rough sets and agents}

By agents and active sets is possible to show that rough sets ${ }^{29-31}$ are natural extension of the evidence theory. In fact in Evidence theory we have only two possible logical values as True or False. In the previous chapter good can be true or false. When good is false we have the class bad. So the two classes good and bad can be interpreted by a set of agents, which evaluate as the classical true and false. Now in rough sets we can have a many valued logic as good medium bad. The evaluation is given by the $\mathrm{V}(\mathrm{p})$ matrix of classical logic value true and false.

$V(p)=\left[\begin{array}{cccc}v_{1,1} & v_{1,2} & \ldots & v_{1, n} \\ \ldots & \ldots & \ldots & \ldots \\ v_{m, 1} & v_{m, 2} & \ldots & v_{m, n}\end{array}\right]$

or

$V\left(\right.$ object $_{k} \in\left(\right.$ agent $_{i}$, class $\left._{j}\right)=K_{i, j}^{k}$

$\left(\begin{array}{ccccc} & \text { agent }_{1} & \text { agent }_{2} & \ldots . & \text { agent }_{n} \\ \text { class }_{1} & v_{1,1} & v_{1,2} & \ldots & v_{1, n} \\ \ldots & \ldots & \ldots & \ldots & \ldots \\ \text { class }_{m} & v_{m .1} & v_{m .2} & \ldots & v_{m, n}\end{array}\right)(18)$

$$
\begin{aligned}
& V\left(\text { object }_{k} \in\left(\text { agent }_{i}, \text { class }_{j}\right)=K_{i, j}^{k}\right. \\
& =\left(\begin{array}{ccccc}
\text { agent }_{1} & \text { agent }_{2} & \ldots . & \text { agent }_{n} \\
\text { class }_{1} & v_{1,1} & v_{1,2} & \ldots & v_{1, n} \\
\ldots & \ldots & \ldots & \ldots & \ldots \\
\text { class }_{m} & v_{m .1} & v_{m .2} & \ldots & v_{m, n}
\end{array}\right)
\end{aligned}
$$

\subsection{Classes as valued in many valued logic}

We can study the classes as symbolic logic values in the Lattice valued Logic. Now we can represent any class as a special active set of agents. The agents in this active set use a set of tests by which we can evaluate the class that we want to detect. So we have

class $_{i}=\left(\begin{array}{ccccc} & \text { test }_{1} & \text { test }_{2} & \ldots & \text { test }_{p} \\ \text { value } & \eta_{i, 1} & \eta_{i, 2} & \ldots & \eta_{i, p}\end{array}\right)$

For example given the table

\begin{tabular}{|l|l|l|l|l|}
\hline Students & math & Ph & Lit & Overall \\
\hline S1 & good & medium & bad & bad \\
\hline S2 & medium & medium & bad & medium \\
\hline S3 & medium & medium & medium & medium \\
\hline S4 & medium & medium & medium & good \\
\hline S5 & good & medium & good & good \\
\hline S6 & good & good & good & good \\
\hline S7 & bad & bad & medium & bad \\
\hline S8 & bad & bad & medium & bad \\
\hline
\end{tabular}

We have three classes. Now given two tests as an example we have

$$
\begin{aligned}
& \text { good }=\left(\begin{array}{ccc} 
& \text { test }_{1} & \text { test }_{2} \\
\text { value } & \text { true } & \text { true }
\end{array}\right), \\
& \text { medium }_{1}=\left(\begin{array}{lll} 
& \text { test }_{1} & \text { test }_{2} \\
\text { value } & \text { false } & \text { true }
\end{array}\right) \\
& \text { medium }_{2}=\left(\begin{array}{ccc} 
& \text { test }_{1} & \text { test }_{2} \\
\text { value } & \text { true } & \text { false }
\end{array}\right) \text {, } \\
& \text { bad }=\left(\begin{array}{lll} 
& \text { test }_{1} & \text { test }_{2} \\
\text { value } & \text { false } & \text { false }
\end{array}\right)
\end{aligned}
$$

So we have the lattice 


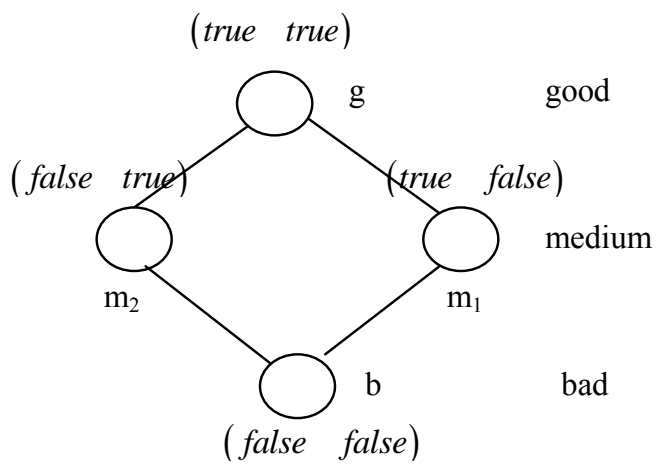

Figure 8. Lattice valued Logic for four logic value as (good, medium 1 , medium 2 , bad).

The OR logic operation for the classes (many valued) $\mathrm{g}, \mathrm{m}_{1}, \mathrm{~m}_{2}$ and $\mathrm{b}$ is

\begin{tabular}{|c|c|c|c|c|}
\hline$v$ & $\left(\begin{array}{ll}t & t\end{array}\right)$ & $\left(\begin{array}{ll}t & f\end{array}\right)$ & $\left(\begin{array}{ll}f & t\end{array}\right)$ & $\left(\begin{array}{ll}f & f\end{array}\right)$ \\
\hline$\left(\begin{array}{ll}t & t\end{array}\right)$ & $\left(\begin{array}{ll}t & t\end{array}\right)$ & $\left(\begin{array}{ll}t & t\end{array}\right)$ & $\left(\begin{array}{ll}t & t\end{array}\right)$ & $\left(\begin{array}{ll}t & t\end{array}\right)$ \\
\hline$\left(\begin{array}{ll}t & f\end{array}\right)$ & $\left(\begin{array}{ll}t & t\end{array}\right)$ & $\left(\begin{array}{ll}t & f\end{array}\right)$ & $\left(\begin{array}{ll}t & t\end{array}\right)$ & $\left(\begin{array}{ll}t & f\end{array}\right)$ \\
\hline$\left(\begin{array}{ll}f & t\end{array}\right)$ & $\left(\begin{array}{ll}t & t\end{array}\right)$ & $\left(\begin{array}{ll}t & t\end{array}\right)$ & $\left(\begin{array}{ll}f & t\end{array}\right)$ & $\left(\begin{array}{ll}f & t\end{array}\right)$ \\
\hline$\left(\begin{array}{ll}f & f\end{array}\right)$ & $\left(\begin{array}{ll}t & t\end{array}\right)$ & $\left(\begin{array}{ll}t & f\end{array}\right)$ & $\left(\begin{array}{ll}f & t\end{array}\right)$ & $\left(\begin{array}{ll}f & f\end{array}\right)$ \\
\hline
\end{tabular}

Now the previous table can be written in this way

\begin{tabular}{|c|c|c|c|c|}
\hline$\vee$ & $\mathrm{g}$ & $\mathrm{m}_{1}$ & $\mathrm{~m}_{2}$ & $\mathrm{~b}$ \\
\hline $\mathrm{g}$ & $\mathrm{g}$ & $\mathrm{g}$ & $\mathrm{g}$ & $\mathrm{g}$ \\
\hline $\mathrm{m}_{1}$ & $\mathrm{~g}$ & $\mathrm{~m}_{1}$ & $\mathrm{~g}$ & $\mathrm{~m}_{1}$ \\
\hline $\mathrm{m}_{2}$ & $\mathrm{~g}$ & $\mathrm{~g}$ & $\mathrm{~m}_{2}$ & $\mathrm{~m}_{2}$ \\
\hline $\mathrm{b}$ & $\mathrm{g}$ & $\mathrm{m}_{1}$ & $\mathrm{~m}_{2}$ & $\mathrm{~b}$ \\
\hline
\end{tabular}

The meaning of the previous classes operations (any class is a logic value), is this :

When one student is good (passes both tests) he will win the mark good. We are not interested in the fail state but only when he passes the test so if the professors wait with patience the important states are not the fail states but only when the students pass the test. At the reverse we have the "AND" operation

\begin{tabular}{|c|c|c|c|c|}
\hline$\wedge$ & $\mathrm{g}$ & $\mathrm{m}_{1}$ & $\mathrm{~m}_{2}$ & $\mathrm{~b}$ \\
\hline $\mathrm{g}$ & $\mathrm{g}$ & $\mathrm{m}_{1}$ & $\mathrm{~m}_{2}$ & $\mathrm{~b}$ \\
\hline $\mathrm{m}_{1}$ & $\mathrm{~m}_{1}$ & $\mathrm{~m}_{1}$ & $\mathrm{~b}$ & $\mathrm{~b}$ \\
\hline $\mathrm{m}_{2}$ & $\mathrm{~m}_{2}$ & $\mathrm{~b}$ & $\mathrm{~m}_{2}$ & $\mathrm{~b}$ \\
\hline $\mathrm{b}$ & $\mathrm{b}$ & $\mathrm{b}$ & $\mathrm{b}$ & $\mathrm{b}$ \\
\hline
\end{tabular}

In this table the fail state is more important. If the student fails the two tests he cannot have a mark superior to bad.

With the Kleene's implication

$\mathrm{A} \Rightarrow \mathrm{B}=\operatorname{not} \mathrm{A}$ or $\mathrm{B}$

we have

\begin{tabular}{|c|c|c|c|c|}
\hline$\Rightarrow$ & $\mathrm{g}$ & $\mathrm{m}_{1}$ & $\mathrm{~m}_{2}$ & $\mathrm{~b}$ \\
\hline $\mathrm{b}$ & $\mathrm{g}$ & $\mathrm{g}$ & $\mathrm{g}$ & $\mathrm{g}$ \\
\hline $\mathrm{m}_{2}$ & $\mathrm{~g}$ & $\mathrm{~m}_{1}$ & $\mathrm{~g}$ & $\mathrm{~m}_{1}$ \\
\hline $\mathrm{m}_{1}$ & $\mathrm{~g}$ & $\mathrm{~g}$ & $\mathrm{~m}_{2}$ & $\mathrm{~m}_{2}$ \\
\hline $\mathrm{g}$ & $\mathrm{g}$ & $\mathrm{m}_{1}$ & $\mathrm{~m}_{2}$ & $\mathrm{~b}$ \\
\hline
\end{tabular}

Where the negation is

$\neg\left[\begin{array}{llll}g & m_{1} & m_{2} & b\end{array}\right]^{T}=\left[\begin{array}{llll}0 & 0 & 0 & 1 \\ 0 & 0 & 1 & 0 \\ 0 & 1 & 0 & 0 \\ 1 & 0 & 0 & 0\end{array}\right]\left[\begin{array}{c}g \\ m_{1} \\ m_{2} \\ b\end{array}\right]=\left[\begin{array}{c}b \\ m_{2} \\ m_{1} \\ g\end{array}\right]$

The implication rule has this meaning. When the student has a good mark and after has medium or bad we lose the control of the examination so the implication is medium or bad. But at the reverse if the mark is bad and after is good or medium then we have a good implication because the student improves the control of the examination.

In the previous example we have always the property shown in Equation 20.

$x \vee x=x \wedge x=x$

Now in the lattice theory we can violate the previous condition so we have

$x \vee x \geq x$

$x \wedge x \leq x$

For example for the lattice 


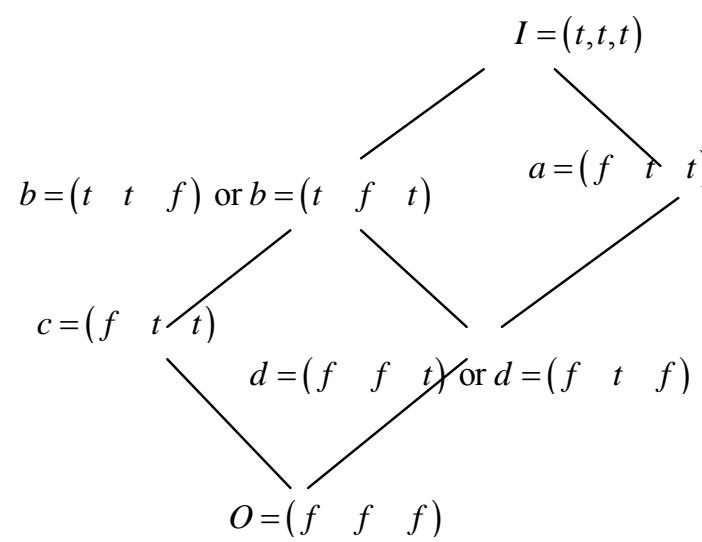

Figure 9. Lattice valued logic, which values $b$ and $d$ have two different representations by active set of tests.

Where

$$
\begin{aligned}
& \left(\begin{array}{lll}
t & t & f
\end{array}\right) \vee\left(\begin{array}{lll}
t & f & t
\end{array}\right)=\left(\begin{array}{lll}
t & t & t
\end{array}\right) \\
& \left(\begin{array}{lll}
f & f & t
\end{array}\right) \vee\left(\begin{array}{lll}
f & t & f
\end{array}\right)=\left(\begin{array}{lll}
f & t & t
\end{array}\right)
\end{aligned}
$$

So the self logic operation $\mathrm{A} \vee \mathrm{A}>\mathrm{A}$ and $\mathrm{A} \wedge \mathrm{A}<$ A.

Now for the Kleene's implication operation we have

\begin{tabular}{|c|l|l|l|l|l|l|}
\hline V & O & a & b & c & d & I \\
\hline I & I & I & I & I & I & I \\
\hline c & c & I & b & c & b & I \\
\hline d & d & a & I & b & a & I \\
\hline a & a & a & I & I & a & I \\
\hline b & b & I & I & b & I & I \\
\hline O & O & a & b & c & d & I \\
\hline
\end{tabular}

Where

$$
b \vee b=I, d \vee d=a
$$

For the negation operator

$$
\left[\begin{array}{l}
O \\
c \\
d \\
a \\
b \\
I
\end{array}\right]=\left[\begin{array}{llllll}
0 & 0 & 0 & 0 & 0 & 1 \\
0 & 0 & 0 & 1 & 0 & 0 \\
0 & 0 & 0 & 0 & 1 & 0 \\
0 & 1 & 0 & 0 & 0 & 0 \\
0 & 0 & 1 & 0 & 0 & 0 \\
1 & 0 & 0 & 0 & 0 & 0
\end{array}\right]\left[\begin{array}{l}
O \\
a \\
b \\
c \\
d \\
I
\end{array}\right]=\operatorname{not}(A)
$$

We have the implication rule

\begin{tabular}{|c|l|l|l|l|l|l|}
\hline$\Rightarrow$ & O & a & b & c & d & I \\
\hline O & I & I & I & I & I & I \\
\hline a & c & I & b & c & b & I \\
\hline b & d & a & I & b & a & I \\
\hline c & a & a & I & I & a & I \\
\hline d & b & I & I & b & I & I \\
\hline I & O & a & b & c & d & I \\
\hline
\end{tabular}

The rule

$$
x \vee x \geq x
$$$$
x \wedge x \leq x
$$

Means that the professor focuses his attention on the result true. If the student result in the test is the same at two different times he give a higher and more optimistic result because he is happy that the student can give the same result many times. So

$b \vee b=I>b$

\subsection{Rough sets by active sets of agents and decision rules}

Given one true value for any colon of the classes in (19) the number of the possible evaluations or configuration (19) are

$$
W=m^{n}
$$

For example with three classes and four agents we have that the number of the possible configurations are

$$
W=3^{4}=81
$$

Among the 81 possible cases we select the 8 possible complex evaluations of the student logic state in this way

$$
\begin{aligned}
& V\left(\text { Student }_{1} \in\left(\text { professor }_{i}, \text { class }_{j}\right)=K_{i, j}^{1}\right. \\
& =\left(\begin{array}{ccccc}
\text { active sets } & \text { Math } & \text { Phys } & \text { Lit } & \text { Overall } \\
\text { good } & \text { true } & \text { false } & \text { false } & \text { false } \\
\text { medium } & \text { false } & \text { true } & \text { false } & \text { false } \\
\text { bad } & \text { false } & \text { false } & \text { true } & \text { true }
\end{array}\right)\left[\begin{array}{c}
\text { number true } \\
1 \\
1 \\
2
\end{array}\right]
\end{aligned}
$$

Logic expressions 


$$
S 1=\left\{\begin{array}{c}
\text { good }=\text { math } \\
\text { medium }=\text { phy } \\
\text { bad }=\text { Overall } \vee \text { Lit }
\end{array}\right.
$$

Active set image for the student S1 and the four agents is shown in Figure 10. black is good, grey is medium and white is bad.

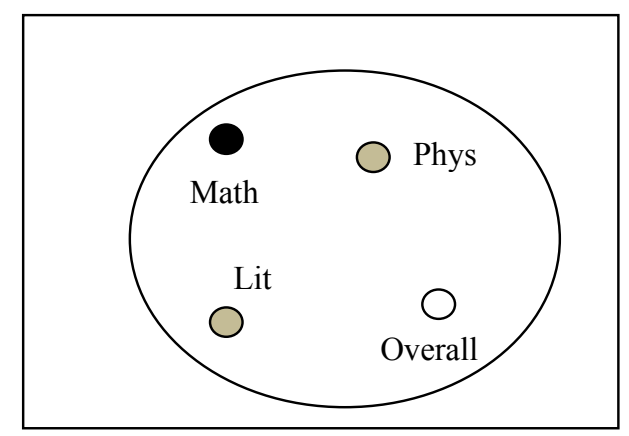

Figure 10. Active set for the student S1

$$
\begin{aligned}
& V\left(\text { Student }_{2} \in\left(\text { professor }_{i}, \text { class }_{j}\right)=K_{i, j}^{2}\right. \\
& =\left(\begin{array}{ccccc}
\text { active sets } & \text { Math } & \text { Phys } & \text { Lit } & \text { Overall } \\
\text { good } & \text { false } & \text { false } & \text { false } & \text { false } \\
\text { medium } & \text { true } & \text { true } & \text { false } & \text { true } \\
\text { bad } & \text { false } & \text { false } & \text { true } & \text { false }
\end{array}\right)\left[\begin{array}{c}
\text { true } \\
0 \\
3 \\
1
\end{array}\right]
\end{aligned}
$$

Logic expressions

$$
S 2=\left\{\begin{aligned}
\text { good } & =\text { false } \\
\text { medium }=\text { Math } & \vee \text { Phys } \vee \text { Overall } \\
\text { bad } & =\text { Lit }
\end{aligned}\right.
$$

For the student S2 we have the active set structure as shown in Figure 11 and Equation 28.

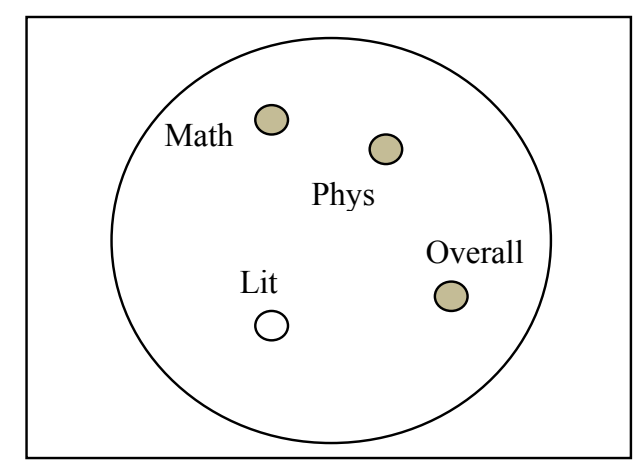

Figure 11. Active set for the student S2

For the other students we have the formal active set image

$$
\begin{aligned}
& V\left(\text { Student }_{3} \in\left(\text { professor }_{i}, \text { class }_{j}\right)=K_{i, j}^{3}\right. \\
& =\left(\begin{array}{ccccc}
\text { active sets } & \text { Math } & \text { Phys } & \text { Lit } & \text { Overall } \\
\text { good } & \text { false } & \text { false } & \text { false } & \text { false } \\
\text { medium } & \text { true } & \text { true } & \text { true } & \text { true } \\
\text { bad } & \text { false } & \text { false } & \text { false } & \text { false }
\end{array}\right)\left[\begin{array}{c}
\text { true } \\
0 \\
4 \\
0
\end{array}\right]
\end{aligned}
$$

Logic expressions

$$
S 3=\left\{\begin{array}{c}
\text { good }=\text { false } \\
\text { medium }=\text { Math } \vee \text { Phys } \vee \text { Lit } \vee \text { Overall } \\
\text { bad }=\text { false }
\end{array}\right.
$$

$$
\begin{aligned}
& V\left(\text { Student }_{4} \in\left(\text { professor }_{i}, \text { class }_{j}\right)=K_{i, j}^{4}\right. \\
& =\left(\begin{array}{cllll}
\text { active sets } & \text { Math } & \text { Phys } & \text { Lit } & \text { Overall } \\
\text { good } & \text { false } & \text { false } & \text { false } & \text { true } \\
\text { medium } & \text { true } & \text { true } & \text { true } & \text { false } \\
\text { bad } & \text { false } & \text { false } & \text { false } & \text { false }
\end{array}\right)\left[\begin{array}{c}
\text { true } \\
1 \\
3 \\
0
\end{array}\right]
\end{aligned}
$$

Logic expressions

$$
S 4=\left\{\begin{array}{c}
\text { good }=\text { Overall } \\
\text { medium }=(\text { Math } \vee \text { Phy } \vee \text { Lite }) \\
\text { bad }=\text { false }
\end{array}\right.
$$




$$
\begin{aligned}
& V\left(\text { Student }_{5} \in\left(\text { professor }_{i}, \text { class }_{j}\right)=K_{i, j}^{5}\right. \\
& =\left(\begin{array}{ccccc}
\text { active sets } & \text { Math } & \text { Phys } & \text { Lit } & \text { Overall } \\
\text { good } & \text { true } & \text { false } & \text { true } & \text { true } \\
\text { medium } & \text { false } & \text { true } & \text { false } & \text { false } \\
\text { bad } & \text { false } & \text { false } & \text { false } & \text { false }
\end{array}\right)\left[\begin{array}{c}
3 \\
1 \\
0
\end{array}\right]
\end{aligned}
$$

Logic expressions

$$
\begin{aligned}
& S 5=\left\{\begin{array}{c}
\text { good }=\text { Math } \vee \text { Lit } \vee \text { Overall } \\
\text { medium }=\text { Phy } \\
\text { bad }=\text { false }
\end{array}\right.
\end{aligned}
$$

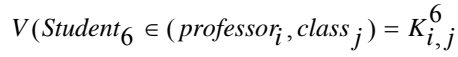

$$
\begin{aligned}
& =\left(\begin{array}{ccccc}
\text { active sets } & \text { Math } & \text { Phys } & \text { Lit } & \text { Overall } \\
\text { good } & \text { true } & \text { true } & \text { true } & \text { true } \\
\text { medium } & \text { false } & \text { false } & \text { false } & \text { false } \\
\text { bad } & \text { false } & \text { false } & \text { false } & \text { false }
\end{array}\right)\left[\begin{array}{c}
\text { true } \\
4 \\
0 \\
0
\end{array}\right]
\end{aligned}
$$

Logic expressions

$$
S 6=\left\{\begin{array}{c}
\text { good }=\text { Math } \vee \text { Phy } \vee \text { Lit } \vee \text { Overall } \\
\text { medium }=\text { false } \\
\text { bad }=\text { false }
\end{array}\right.
$$

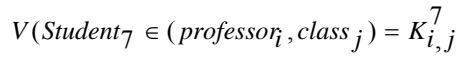

$$
=\left(\begin{array}{ccccc}
\text { active sets } & \text { Math } & \text { Phys } & \text { Lit } & \text { Overall } \\
\text { good } & \text { false } & \text { false } & \text { false } & \text { false } \\
\text { medium } & \text { false } & \text { false } & \text { true } & \text { false } \\
\text { bad } & \text { true } & \text { true } & \text { false } & \text { true }
\end{array}\right)\left[\begin{array}{c}
0 \\
1 \\
3
\end{array}\right]
$$

Logic expression

$$
\mathrm{S} 7=\left\{\begin{array}{c}
\text { good }=\text { false } \\
\text { medium }=\text { Lit } \\
\text { bad }=\text { Math } \vee \text { Phys } \vee \text { Overall }
\end{array}\right.
$$

$$
\begin{aligned}
& V\left(\text { Student }_{8} \in\left(\text { professor }_{i}, \text { class }_{j}\right)=K_{i, j}^{8}\right. \\
& =\left(\begin{array}{ccccc}
\text { active sets } & \text { Math } & \text { Phys } & \text { Lit } & \text { Overall } \\
\text { good } & \text { false } & \text { false } & \text { false } & \text { false } \\
\text { medium } & \text { false } & \text { false } & \text { true } & \text { false } \\
\text { bad } & \text { true } & \text { true } & \text { false } & \text { true }
\end{array}\right)\left[\begin{array}{c}
\text { true } \\
0 \\
1 \\
3
\end{array}\right]
\end{aligned}
$$

$$
\mathrm{S} 8=\left\{\begin{array}{c}
\text { good }=\text { false } \\
\text { medium }=\text { Lit } \\
\text { bad }=\text { Math } \vee \text { Phys } \vee \text { Overall }
\end{array}\right.
$$

We remark that the students 7 and 8 have the same evaluation so are indiscernible.

Given the class "good" in rough set theory we have this approximation for the class "good"

$$
\begin{aligned}
& \text { lower approximation }=\left\{S_{6}, S_{5}\right\} \\
& \text { upper approximation }=\left\{S_{6}, S_{5}, S_{4}, S_{3}\right\}
\end{aligned}
$$

Now we will show this rough set property by active sets. All the logic systems where good is true for 4 and three agents are

$$
\begin{gathered}
S 6=\left\{\begin{array}{c}
\text { good }=\text { Math } \vee \text { Phys } \vee \text { Lit } \vee \text { Overall } \\
\text { medium }=\text { false } \\
\text { bad }=\text { false }
\end{array}\right. \\
S 5=\left\{\begin{array}{c}
\text { good }=\text { Math } \vee \text { Lit } \vee \text { Overall } \\
\text { medium }=\text { Phys } \\
\text { bad }=\text { false }
\end{array}\right.
\end{gathered}
$$

The active set where overall is good as in S6, S5 is

$$
S 4=\left\{\begin{array}{c}
\text { good }=\text { Overall } \\
\text { medium }=(\text { Math } \vee \text { Phys } \vee \text { Lit }) \\
\text { bad }=\text { false }
\end{array}\right.
$$

The system where bad is always false and good is always false but has common value medium with $\mathrm{S} 6, \mathrm{~S} 5, \mathrm{~S} 4$ is

$$
S 3=\left\{\begin{array}{c}
\text { good }=\text { false } \\
\text { medium }=\text { Math } \vee \text { Phy } \vee \text { Lite } \vee \text { Overall } \\
\text { bad }=\text { false }
\end{array}\right.
$$

The active sets are shown in Figure 12. 


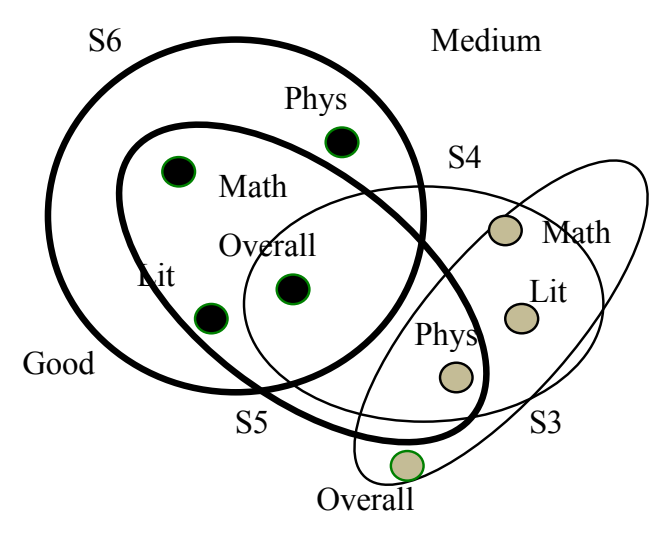

Figure 12. Active sets S6, S5, where good is true in the most of the cases is the lower approximation. The upper approximation includes S4 that has a non empty intersection with S5 and S3 that has a non empty intersection with S4. Now we show by active sets one example of the decision rule.

premise Literature $=$ good

The premise can be represented in figure 13 .

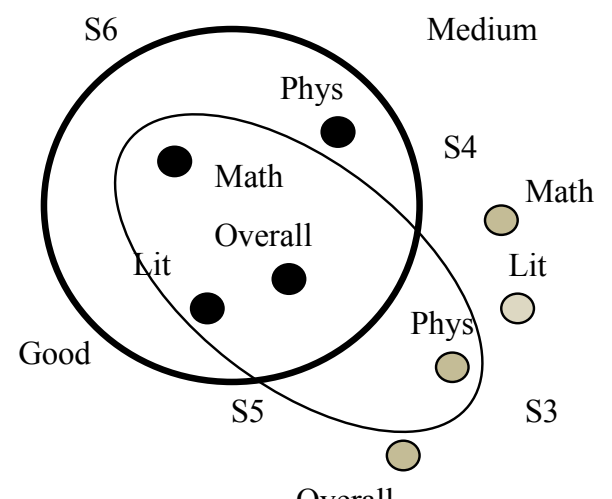

Overall

Figure 13. Active sets S6, S5 for the premise decision rule Literature $=$ good.

The conclusion of the rule is:

Student is good for almost all the professors so the students are certainly good.

Certainty condition is given by the rule:

If the intersection of two active sets associated with two classes cover more that $50 \%$ of one class the student belongs certainly at the class at the intersection.

Another example of the decision rule:

Premise of the rule

Literature $=$ medium, Physics $=$ medium

The active set representation of the premise is shown in Figure 14.

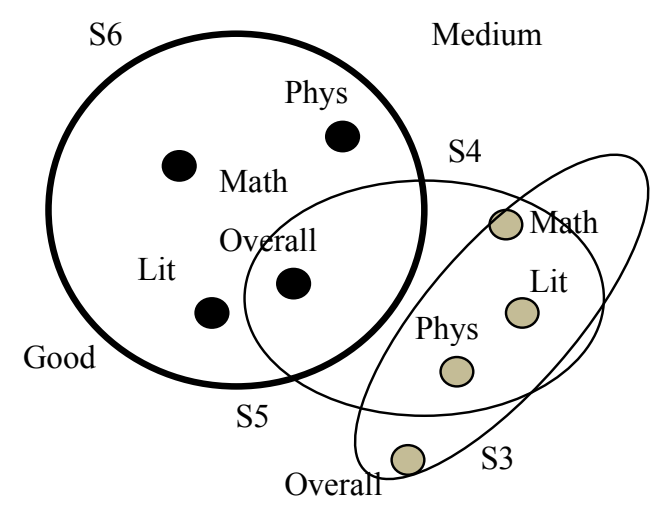

Figure 14. Active sets representation of the condition Literature $=$ medium, Physics $=$ medium .

The conclusion is

The student is possibly good in S4 but student is medium for S3.

Another example of the decision rule by active set of agents is shown in Figure 15.

Rule math $=$ good, Lit $=$ bad

$S 1=\left\{\begin{array}{c}\text { good }=\text { math } \\ \text { medium }=\text { phy } \\ \text { bad }=\text { Overall } \vee \text { Lit }\end{array}\right.$ 


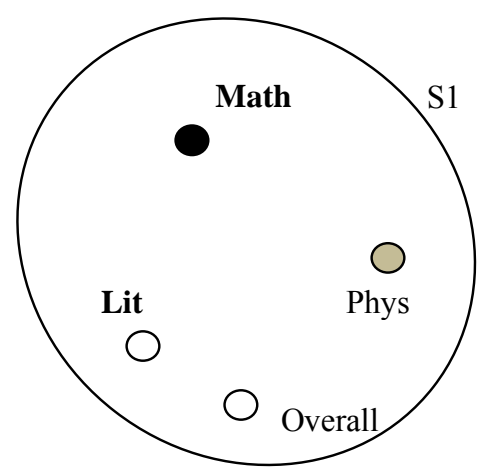

Figure 15. Active sets representation of the condition Math $=$ good, Lit $=$ bad.

S1 is certainly bad because in Figure 15 we have two agents with value "bad"

Another example of the decision rule

Premise Math $=$ medium, Lit $=$ bad

$S 2=\left\{\begin{array}{c}\text { good }=\text { false } \\ \text { medium }=\text { Math } \vee \text { Phys } \vee \text { Overall } \\ \text { bad }=\text { Lit }\end{array}\right.$

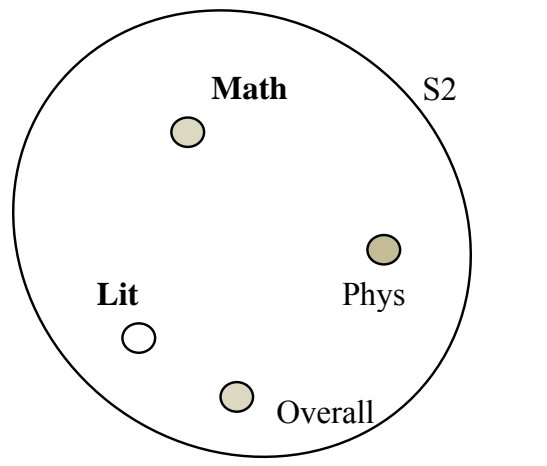

Figure 16. Active sets representation of the condition math $=$ medium, Lit $=$ bad.

$\mathrm{S} 2$ is certainly medium because in figure 10 we have for agent with value medium

Certain decision rules based on indiscernibility are inconsistent with respect to the dominance principle (monotonicity constraints), we will compute this inconsistency by this composition rule (34) between active sets

$F\left(S_{i}, S_{j}\right)=\left(\begin{array}{c}c_{1} \\ c_{2} \\ \ldots \\ c_{n}\end{array}\right)^{T}\left(\left(S_{i}>S_{j}\right)-\left(S_{j}<S_{i}\right)\right)$

In the expression we have that

$S_{i}>S_{j}$

Is a filter of the logic structure of the student $S_{i}$. In fact in $S_{i}>S_{j}$ we select the values in $\mathrm{S}_{\mathrm{i}}$ that are different from the other. And reverse for $S_{i}<S_{j}$. The vector

$\left(\begin{array}{l}c_{1} \\ c_{2} \\ \cdots \\ c_{n}\end{array}\right)$

Is a numerical vector that has the same order of the classes.

For example for

$S 1=\left[\begin{array}{llll}1 & 0 & 0 & 0 \\ 0 & 1 & 0 & 0 \\ 0 & 0 & 1 & 1\end{array}\right], S 2=\left[\begin{array}{llll}0 & 0 & 0 & 0 \\ 1 & 1 & 0 & 1 \\ 0 & 0 & 1 & 0\end{array}\right]$

We have 


$$
\begin{aligned}
& S 1=\left[\begin{array}{llll}
1 & 0 & 0 & 0 \\
0 & 1 & 0 & 0 \\
0 & 0 & 1 & 1
\end{array}\right], S 2=\left[\begin{array}{llll}
0 & 0 & 0 & 0 \\
1 & 1 & 0 & 1 \\
0 & 0 & 1 & 0
\end{array}\right] \\
& F(S 1, S 2)=\left[\begin{array}{l}
3 \\
2 \\
1
\end{array}\right]^{T}\left(\left(\left[\begin{array}{llll}
1 & 0 & 0 & 0 \\
0 & 1 & 0 & 0 \\
0 & 0 & 1 & 1
\end{array}\right]>\left[\begin{array}{llll}
0 & 0 & 0 & 0 \\
1 & 1 & 0 & 1 \\
0 & 0 & 1 & 0
\end{array}\right]\right)\right. \\
& \left.-\left(\left[\begin{array}{llll}
1 & 0 & 0 & 0 \\
0 & 1 & 0 & 0 \\
0 & 0 & 1 & 1
\end{array}\right]<\left[\begin{array}{llll}
0 & 0 & 0 & 0 \\
1 & 1 & 0 & 1 \\
0 & 0 & 1 & 0
\end{array}\right]\right)\right) \\
& =\left[\begin{array}{l}
3 \\
2 \\
1
\end{array}\right]^{T}\left(\left[\begin{array}{llll}
1 & 0 & 0 & 0 \\
0 & 0 & 0 & 0 \\
0 & 0 & 0 & 1
\end{array}\right]-\left[\begin{array}{llll}
0 & 0 & 0 & 0 \\
1 & 0 & 0 & 1 \\
0 & 0 & 0 & 0
\end{array}\right]\right) \\
& =\left[\begin{array}{l}
3 \\
2 \\
1
\end{array}\right]^{T}\left(\left[\begin{array}{cccc}
1 & 0 & 0 & 0 \\
-1 & 0 & 0 & -1 \\
0 & 0 & 0 & 1
\end{array}\right]\right)=\left[\begin{array}{llll}
1 & 0 & 0 & -1
\end{array}\right]
\end{aligned}
$$

Where

$S_{1}=[$ good medium bad bad $]$

$S_{2}=[$ medium medium bad medium $]$

$S_{1}>S_{2}=[\operatorname{good} \quad 0 \quad 0 \quad$ bad $]$

$S_{2}>S_{1}=[$ medium 000 medium $]$

Now we put

$$
\left[\begin{array}{c}
\text { good } \\
\text { medium } \\
\text { bad }
\end{array}\right] \approx\left[\begin{array}{l}
3 \\
2 \\
1
\end{array}\right]
$$

And

$$
\begin{aligned}
& \left(S_{1}>S_{2}\right)-\left(\mathrm{S}_{1}<S_{2}\right) \\
& \text { [good } 000 \text { bad]-[medium } 0000 \text { medium }] \\
& {\left[\begin{array}{ccccc}
\text { good } & 1 & 0 & 0 & 0 \\
\text { medium } & 0 & 0 & 0 & 0 \\
\text { bad } & 0 & 0 & 0 & 1
\end{array}\right]-\left[\begin{array}{ccccc}
\text { good } & 0 & 0 & 0 & 0 \\
\text { medium } & 1 & 0 & 0 & 1 \\
\text { bad } & 0 & 0 & 0 & 0
\end{array}\right]} \\
& =\left[\begin{array}{ccccc}
\text { good } & 1 & 0 & 0 & 0 \\
\text { medium } & -1 & 0 & 0 & -1 \\
\text { bad } & 0 & 0 & 0 & 1
\end{array}\right]
\end{aligned}
$$

Now good as value 3 and medium as value 2 so we have the differences

$$
\begin{aligned}
& {\left[\begin{array}{l}
3 \\
2 \\
1
\end{array}\right]^{T}\left[\begin{array}{c}
1 \\
-1 \\
0
\end{array}\right]=\left[\begin{array}{lll}
3 & 2 & 1
\end{array}\right]\left[\begin{array}{c}
1 \\
-1 \\
0
\end{array}\right]} \\
& =(3)(1)+(2)(-1)+(1)(0)=1 \\
& \text { good }>\text { medium } \\
& \text { and } \\
& {\left[\begin{array}{l}
3 \\
2 \\
1
\end{array}\right]^{T}\left[\begin{array}{c}
0 \\
-1 \\
1
\end{array}\right]=-2+1=-1} \\
& \text { bad < medium }
\end{aligned}
$$

So when we compare S1 with S2 we have a conflicting situation for which when we decrease the value from good to medium, we have as overall or result an increase in the value from bad to medium and this is inconsistent or non monotonic.

\section{Dominance-based rough set approach and agents}

Now we study the relation that we have between the active sets theory and dominance with its rule.

\subsection{Dominance-based and Agents}

Given the map in Figure 15 for the three object ${ }_{1}$, four object $_{2}$ and three object 3

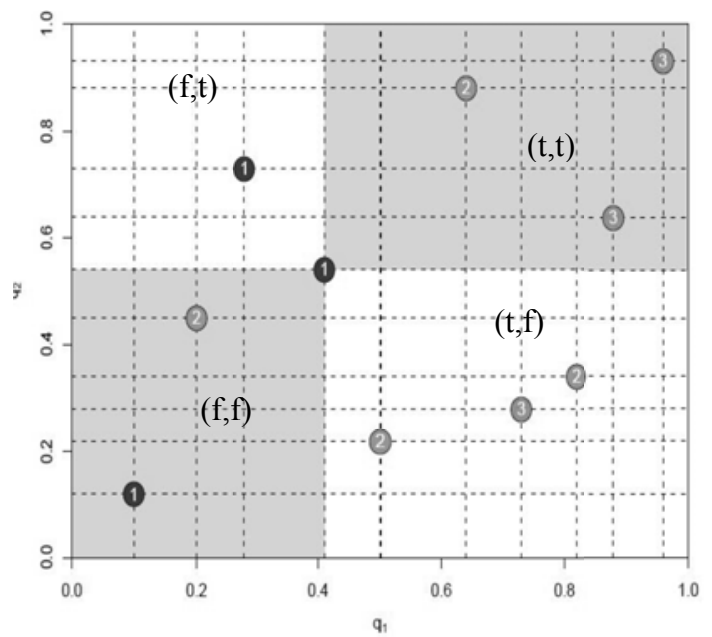

Figure 15. Dominance map.

With active set theory for the three elements of the object $_{1}$ 


$$
\text { Object }_{1}=\left(\begin{array}{ccccc} 
& & 1 & 2 & 3 \\
(t & t) & f & t & f \\
(t & f) & f & t & f \\
(f & t) & t & t & f \\
(f & f) & f & t & t
\end{array}\right)
$$

The first element of the object ${ }_{1}$ is located in place $(f, t)$, the second element of the object ${ }_{1}$ is at the frontier of $(t, t),(t, f),(f, t),(f, f)$, the last element of the object ${ }_{1}$ is inside the zone $(\mathrm{f}, \mathrm{f})$.

In the active set we denote $(1,2,3)$ as the elements of the object ${ }_{1}$. We remark that the element two of the b object 1 is at the frontier of the four parts of the two dimensional space. So element two belongs to the four classes (parts of the space) at the same time. Figure 18 shows this graphically.

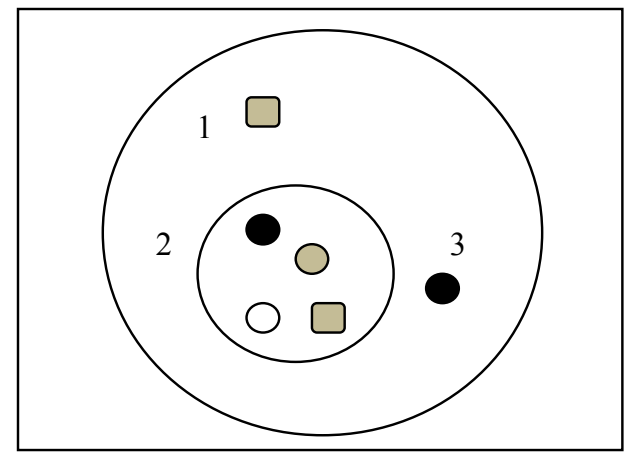

Figure 18. Active sets representation of the dominance in the map of the figure 11 for the object one.

Where black is the class $(t, t)$, grey round is the class $(t, f)$, grey square is the class $(f, t)$ and white is the class ( $\mathrm{f}, \mathrm{f}$ )

For the second object we have four elements in Figure 18. The active set is

$$
\text { Object }_{2}=\left(\begin{array}{llllll} 
& & 1 & 2 & 3 & 4 \\
(t & t) & t & f & f & f \\
(t & f) & f & t & t & f \\
(f & t) & f & f & f & f \\
(f & f) & f & f & f & t
\end{array}\right)
$$

The graph is shown in Figure 19.

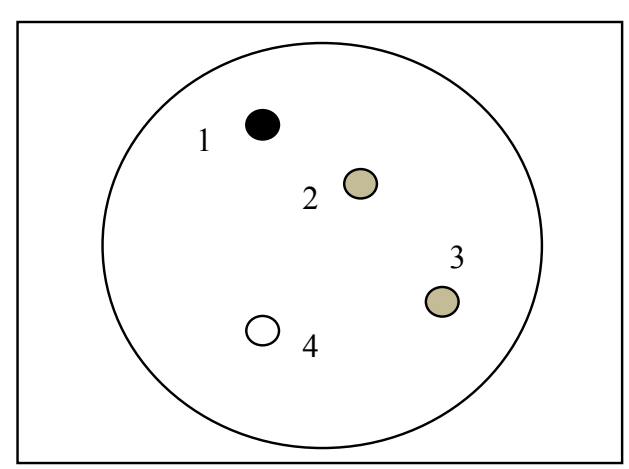

Figure 19. Active sets representation of the dominance in the map of figure 11 for object two.

The third object has three elements so we have the active set

$$
\text { Object }_{3}=\left(\begin{array}{lllll} 
& & 1 & 2 & 3 \\
(t & t) & t & t & f \\
(t & f) & f & f & t \\
(f & t) & f & f & f \\
(f & f) & f & f & f
\end{array}\right)
$$

The graph of this object is shown in Figure 20

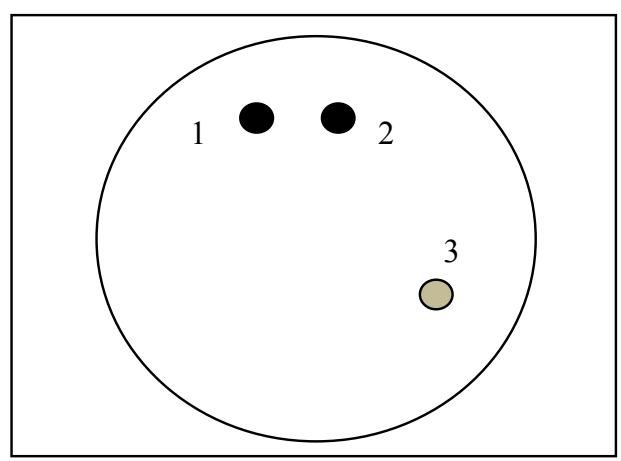

Figure 20. Active sets representation of the dominance in the map of Figure 21 for object three.

By the active sets we have

$$
\text { Object }_{3}=\left(\begin{array}{ccccc} 
& & 1 & 2 & 3 \\
(t & t) & t & t & f \\
(t & f) & f & t & t \\
(f & f) & f & f & f
\end{array}\right)
$$


For the map shown in Figure 21 we have the objects shown in Equations (35-37)

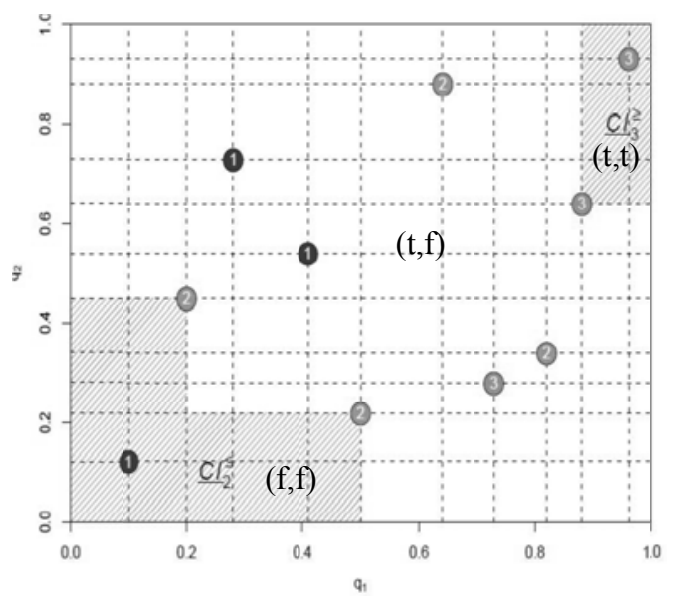

Figure 21. Dominance map.

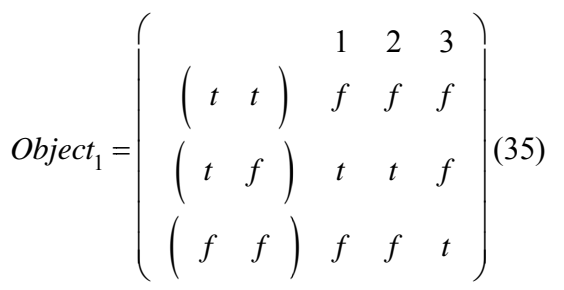

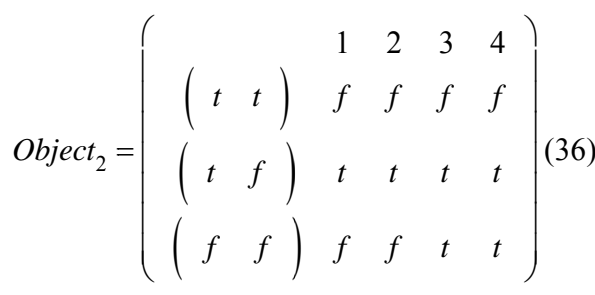

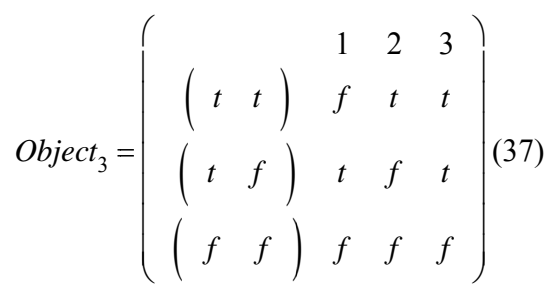

At the border of the three regions (classes) we have that the same element include many classes and not only one class or position $(t, t),(t, f),(f, t),(f, f)$.

\subsection{Dominance-based rules matrix logic computation}

Given the eight students evaluation by the matrices

$$
\begin{aligned}
& S 1=\left[\begin{array}{llll}
1 & 0 & 0 & 0 \\
0 & 1 & 0 & 0 \\
0 & 0 & 1 & 1
\end{array}\right], S 2=\left[\begin{array}{llll}
0 & 0 & 0 & 0 \\
1 & 1 & 0 & 1 \\
0 & 0 & 1 & 0
\end{array}\right], \\
& S 3=\left[\begin{array}{llll}
0 & 0 & 0 & 0 \\
1 & 1 & 1 & 1 \\
0 & 0 & 0 & 0
\end{array}\right], S 4=\left[\begin{array}{llll}
0 & 0 & 0 & 1 \\
1 & 1 & 1 & 0 \\
0 & 0 & 0 & 0
\end{array}\right] \\
& S 5=\left[\begin{array}{llll}
1 & 0 & 1 & 1 \\
0 & 1 & 0 & 0 \\
0 & 0 & 0 & 0
\end{array}\right], S 6=\left[\begin{array}{llll}
1 & 1 & 1 & 1 \\
0 & 0 & 0 & 0 \\
0 & 0 & 1 & 1
\end{array}\right], \\
& S 7=\left[\begin{array}{llll}
0 & 0 & 0 & 0 \\
0 & 0 & 1 & 0 \\
0 & 1 & 0 & 1
\end{array}\right], S 8=\left[\begin{array}{llll}
0 & 0 & 0 & 0 \\
0 & 0 & 1 & 0 \\
1 & 1 & 0 & 1
\end{array}\right]
\end{aligned}
$$

Where 1 is the true value and 0 is the false value in the chapter 2 of rough set definition.

In the previous sections we define the active set for the student S1 and for good, medium and bad

$$
\begin{aligned}
& V\left(\text { Student }_{1} \in\left(\text { professor }_{i}, \text { class }_{j}\right)=K_{i, j}^{1}\right. \\
& =\left(\begin{array}{cccc}
\text { active sets } & \text { Math } & \text { Phys Lit } & \text { Overall } \\
\text { good } & \text { true false false } & \text { false } \\
\text { medium } & \text { false true false } & \text { false } \\
\text { bad } & \text { false false true } & \text { true }
\end{array}\right)
\end{aligned}
$$

where the four columns are math, phys, lit and overall or conclusion. So we put constrains on the math, phys and lit variables and we consider the Overall as the conclusion of the decision rule. We show the active set interpretation examples of decision rules.

Now given the premise

mathematics $\succ=$ good, Literature $\succ=$ medium

We can select the students 


$$
\begin{aligned}
S 4 & =\left[\begin{array}{llll}
0 & 0 & 0 & 1 \\
1 & 1 & 1 & 0 \\
0 & 0 & 0 & 0
\end{array}\right] S 5=\left[\begin{array}{llll}
1 & 0 & 1 & 1 \\
0 & 1 & 0 & 0 \\
0 & 0 & 0 & 0
\end{array}\right], \\
S 6 & =\left[\begin{array}{llll}
1 & 1 & 1 & 1 \\
0 & 0 & 0 & 0 \\
0 & 0 & 0 & 0
\end{array}\right],
\end{aligned}
$$

And with the union operation we have the conclusion

$$
\begin{aligned}
& S 4 \vee S 5 \vee S 6= \\
& {\left[\begin{array}{llll}
0 & 0 & 0 & 1 \\
1 & 1 & 1 & 0 \\
0 & 0 & 0 & 0
\end{array}\right] \vee\left[\begin{array}{llll}
1 & 0 & 1 & 1 \\
0 & 1 & 0 & 0 \\
0 & 0 & 0 & 0
\end{array}\right] \vee\left[\begin{array}{llll}
1 & 1 & 1 & 1 \\
0 & 0 & 0 & 0 \\
0 & 0 & 0 & 0
\end{array}\right]} \\
& =\left[\begin{array}{llll}
1 & 1 & 1 & 1 \\
1 & 1 & 1 & 0 \\
0 & 0 & 0 & 0
\end{array}\right]
\end{aligned}
$$

That formally can write in this way

Then student $=$ good.

Now given the premise

mathematics $\succ=$ medium,

Literature $\succ=$ medium

We can select the students

$$
\begin{aligned}
S 3 & =\left[\begin{array}{llll}
0 & 0 & 0 & 0 \\
1 & 1 & 1 & 1 \\
0 & 0 & 0 & 0
\end{array}\right], S 4=\left[\begin{array}{llll}
0 & 0 & 0 & 1 \\
1 & 1 & 1 & 0 \\
0 & 0 & 0 & 0
\end{array}\right], \\
S 5 & =\left[\begin{array}{llll}
1 & 0 & 1 & 1 \\
0 & 1 & 0 & 0 \\
0 & 0 & 0 & 0
\end{array}\right], S 6=\left[\begin{array}{llll}
1 & 1 & 1 & 1 \\
0 & 0 & 0 & 0 \\
0 & 0 & 0 & 0
\end{array}\right]
\end{aligned}
$$

And with the union operation we have the conclusion
$S 3 \vee S 4 \vee S 5 \vee S 6=$

$\left[\begin{array}{llll}0 & 0 & 0 & 0 \\ 1 & 1 & 1 & 1 \\ 0 & 0 & 0 & 0\end{array}\right] \vee\left[\begin{array}{cccc}0 & 0 & 0 & 1 \\ 1 & 1 & 1 & 0 \\ 0 & 0 & 0 & 0\end{array}\right] \vee$

$\vee\left[\begin{array}{llll}1 & 0 & 1 & 1 \\ 0 & 1 & 0 & 0 \\ 0 & 0 & 0 & 0\end{array}\right] \vee\left[\begin{array}{llll}1 & 1 & 1 & 1 \\ 0 & 0 & 0 & 0 \\ 0 & 0 & 0 & 0\end{array}\right]$

$=\left[\begin{array}{llll}1 & 1 & 1 & 1 \\ 1 & 1 & 1 & 1 \\ 0 & 0 & 0 & 0\end{array}\right]$

That formally can write in this way

Then student $>=$ medium for overall column

Now given the premise

mathematics $\succ=$ good, Literature $=$ bad

We can select the students

$$
\begin{aligned}
S 4 & =\left[\begin{array}{llll}
0 & 0 & 0 & 1 \\
1 & 1 & 1 & 0 \\
0 & 0 & 0 & 0
\end{array}\right], S 5=\left[\begin{array}{llll}
1 & 0 & 1 & 1 \\
0 & 1 & 0 & 0 \\
0 & 0 & 0 & 0
\end{array}\right], \\
S 6 & =\left[\begin{array}{llll}
1 & 1 & 1 & 1 \\
0 & 0 & 0 & 0 \\
0 & 0 & 0 & 0
\end{array}\right],
\end{aligned}
$$

And with the union operation we have the conclusion

$S 4 \vee S 5 \vee S 6=$

$\left[\begin{array}{llll}0 & 0 & 0 & 1 \\ 1 & 1 & 1 & 0 \\ 0 & 0 & 0 & 0\end{array}\right] \vee\left[\begin{array}{llll}1 & 0 & 1 & 1 \\ 0 & 1 & 0 & 0 \\ 0 & 0 & 0 & 0\end{array}\right] \vee\left[\begin{array}{llll}1 & 1 & 1 & 1 \\ 0 & 0 & 0 & 0 \\ 0 & 0 & 0 & 0\end{array}\right]$

$=\left[\begin{array}{llll}1 & 1 & 1 & 1 \\ 1 & 1 & 1 & 0 \\ 0 & 0 & 0 & 0\end{array}\right]$

That formally can write in this way

Then student $=$ good. for overall column

Now given the premise

mathematics $\succ=$ medium,

Literature $\succ=$ medium 
We can select the students

$$
S 1=\left[\begin{array}{llll}
1 & 0 & 0 & 0 \\
0 & 1 & 0 & 0 \\
0 & 0 & 1 & 1
\end{array}\right], S 2=\left[\begin{array}{llll}
0 & 0 & 0 & 0 \\
1 & 1 & 0 & 1 \\
0 & 0 & 1 & 0
\end{array}\right]
$$

And with the union we have the conclusion

$S 1 \vee S 2=\left[\begin{array}{llll}1 & 0 & 0 & 0 \\ 1 & 1 & 1 & 1 \\ 0 & 0 & 1 & 1\end{array}\right]$

That formally can write in this way

Then student is bad or medium for overall column

\section{Dominance-based rules by matrix numerical computation}

Given the numerical analogy

$$
\left[\begin{array}{c}
\text { good } \\
\text { medium } \\
\text { bad }
\end{array}\right] \approx\left[\begin{array}{l}
3 \\
2 \\
1
\end{array}\right]
$$

The table of the student for math, phys, Lit can be written by this matrix

$$
A=\left[\begin{array}{lll}
3 & 2 & 2 \\
2 & 2 & 1 \\
2 & 2 & 2 \\
2 & 2 & 2 \\
3 & 2 & 3 \\
3 & 3 & 3 \\
1 & 1 & 2
\end{array}\right]
$$

and the overall as

$$
b=\left[\begin{array}{l}
1 \\
2 \\
2 \\
3 \\
3 \\
3 \\
1
\end{array}\right]
$$

Now we want to solve the equation

$$
\mathrm{A} x=\mathrm{b}
$$

This equation cannot solved because we do not have the inverse matrix of A. Now we can change the previous equation in a way to have the pseudo inverse in this way

$$
A^{T} A x=A^{T} b
$$

So we have

$x=\left(A^{T} A\right)^{-1} A^{T} b$

Where

$$
A^{T} A=\left[\begin{array}{lll}
40 & 34 & 33 \\
34 & 30 & 29 \\
33 & 29 & 32
\end{array}\right]
$$

Is the self and cross relations among the three professors math $(\mathrm{M})$, phys $(\mathrm{P})$ and Lit $(\mathrm{L})$ and the relations between professor and overall.

The diagonal part is

$$
\left[\begin{array}{cccc} 
& M & P h & L \\
M & 40 & 0 & 0 \\
P h & 0 & 30 & 0 \\
L & 0 & 0 & 38
\end{array}\right]
$$

Where we have the math has the max variation in the marks (good, medium, bad) and $\mathrm{Ph}$ has the minimum variation. Now for the correlation or entanglement or synchronisation of the math professor with the others and with the conclusion is

$$
\left[\begin{array}{cccc} 
& M & P h & L \\
M & 0 & 34 & 33 \\
P h & 34 & 0 & 27 \\
L & 33 & 27 & 0
\end{array}\right]
$$

We remark that $M$ the minimum relation is between $\mathrm{Ph}$ and Literature only 27. The max correlation as is intuitive is between math and Physics professor for which we have 34 . We are not surprised to see that we have a relative good relation between mathematic professor and the Literature professor for which we have 33 .

now if 
$\mathrm{b}=\mathrm{Ax}$

we have

$\left(A^{T} A\right)^{-1} A^{T} A x=x$

Now from the table of the student we have

$$
x=\left[\begin{array}{cc}
\text { math } & -0.23 \\
\text { phy } & 0.816 \\
\text { Lit } & 0.529
\end{array}\right]
$$

For math we have a negative value and this means that math generate a lot of inconsistency because has a negative value on the conclusion or overall. Physics is the most consistent element and is the more important professor that give the final conclusion or overall. The Literature professor is not so important as physics in the definition of the result but does not generate inconsistency because has a weight that is positive. Now by the $\mathrm{x}$ we can compute the vector $b$ ' that is

$\mathrm{A} x=\mathrm{b} 1$

Where

$$
b 1=\left[\begin{array}{c}
1.471 \\
1.701 \\
2.23 \\
2.23 \\
2.529 \\
3.345 \\
1.644
\end{array}\right]
$$

The lapse between student $\mathrm{S} 1$ and $\mathrm{S} 2$ is reduced the minimum inconsistency. For S2, S3 we have no inconsistency so the lapse is near to one. Now for the three professors the student S3 and S4 are equal so is irrational to have as overall the values medium and good. The marks for S5, S6, S7 are in agreement with the conclusion overall. Now given a new student to be evaluated.

\begin{tabular}{|c|c|c|c|}
\hline Student & Mathematics & Physics & Literature \\
\hline S9 & medium & medium & good \\
\hline
\end{tabular}

In this case the matrix $A$ is increased by a new student so we have a new matrix $\mathrm{B}$ given by the explicit form
$B=\left[\begin{array}{lll}3 & 2 & 2 \\ 2 & 2 & 1 \\ 2 & 2 & 2 \\ 2 & 2 & 2 \\ 3 & 2 & 3 \\ 3 & 3 & 3 \\ 1 & 1 & 2 \\ 2 & 2 & 3\end{array}\right]$

With the value of $x$ we can compute the result $b$ by the expression

$\mathrm{Bx}=\mathrm{b} 2$

So we have the new $b=b 2$

$b 2=\left[\begin{array}{c}1.471 \\ 1.701 \\ 2.23 \\ 2.23 \\ 2.529 \\ 3.345 \\ 1.644 \\ 2.759\end{array}\right]$

In agreement with the other students the valuation for the new student is 2.759 or with approximation we have "good". In conclusion for the new student we have

\begin{tabular}{|c|c|l|c|c|}
\hline student & math & Physics & Literature & Overall \\
\hline S9 & medium & medium & good & good \\
\hline
\end{tabular}

\section{Conclusion}

With the suggestion of the paper Dominance-based Rough Set Approach to Reasoning about Vague Data and with the introduction of the agents in the active set theory, we give a new image of the rough set with a formal logic description of the vague or approximate data. Connection with evidence theory and many valued logic by lattice evaluation gives us a more general image of the rough sets and reasoning. Compensation of the inconsistency in rough set approximation is used to give reasoning for new data in agreement with previous vague data. Because active set was used also for fuzzy set model we suggest a bridge between fuzzy set, rough set and active set. 


\section{References}

1. Resconi G. and Jain, L. (2004) Intelligent agents, Springer Verlag

2. Resconi, G., Klir G.J., and U. St. Clair, (1992) Hierarchical uncertainty metatheory based upon modal logic. International Journal of General Systems 21 (23$50)$.

3. Resconi, G., Klir G.J., U. St. Clair, and D.Harmanec. (1993). The integration of uncertainty theories. International Journal of Uncertainty, Fuzziness and Knowledge-Based Systems 1, 1-18.

4. Resconi, G., Klir G.J Harmanec, D. and U. St. Clair. (1996). Interpretation of various uncertainty theories using models of modal logic: a summary, Fuzzy Sets and Systems 80, 7-14

5. Harmanec, D., Resconi, G., Klir, G. J. and Pan, Y.. (1995). On the computation of uncertainty measure in Dempster-Shafer theory, International Journal General Systems, vol.25 (2). 153-163.

6. Resconi, G., Murai, T. and Shimbo, M. (2000). Field Theory and Modal Logic by Semantic field to make Uncertainty Emerge from Information, International Journal of General Systems, vol 29 (5), 737-782.

7. Resconi G. and Turksen I.B. (2001). Canonical Forms of Fuzzy Truthoods by Meta-Theory Based Upon Modal Logic, Information Sciences 131, 157-194. Elsevier

8. Resconi G. and Kovalerchuk, B. (2006). The Logic of Uncertainty with Irrational Agents In: Proc. of JCIS2006 Advances in Intelligent Systems Research, Taiwan, Atlantis Press

9. Kahneman, D. (2003). Maps of Bounded Rationality: Psychology for Behavioral Economics. The American Economic Review. 93(5), 1449-1475.

10.Kovalerchuk B., (1990). Analysis of Gaines' logic of uncertainty, In: Proceeding of NAFIPS ' 90 vol.2 edited by I.B. Turksen, Toronto, Canada, pp. 293-295.

11.Kovalerchuk B. (1996). Context spaces as necessary frames for correct approximate reasoning. International Journal of General Systems, v.25, n 1, 61-80.

12.Kovalerchuk B. and Vityaev E. (2000). Data mining in finance: advances in relational and hybrid methods, Kluwer

13.Baldwin, J. (1991). A theory of mass assignments for artificial intelligence. In: Fuzzy Logic and Fuzzy Control. pp. 22-34. IJCAI'91 Workshops on fuzzy logic and fuzzy control, Springer-Verlag, Sydney, Australia (Jan 1991)

14.Baldwin, J. (1994). A calculus for mass assignments in evidential reasoning. In: Yager, R., Fedrizzi, M., Kacprzyk, J. (eds.) Advances in the Dempster-Shafer Theory of Evidence, pp. 513-531. John Wiley \& Sons, Inc., New York (1994)

15.Baldwin, J.F., Martin, T. and Pilsworth, B. (1995). Fril - Fuzzy and Evidential Reasoning in Artificial Intelligence. Research Studies Press Ltd, Taunton UK (1995)

16.Hinde, C.J. (1993) Inference of Fuzzy Relational Tableaux from Fuzzy Exemplifications. Fuzzy Sets and Systems 11, 91-101.
17.Hinde, C.J., (2009) Intuitionistic Fuzzy Set, Interval Valued Fuzzy Sets and Mass Assignment: a Unifying Treatment including Inconsistency and Contradiction. International Journal of Computational Intelligence Research 4(4), 372-391

18.Hinde, C.J., (2009) Knowledge from Contradiction and Inconsistency. In: Atanassow, K., Baczynski, M., Drewniak, J., Kacprzyk, J., Krawczak, M., Szmidt, E., Wygralak, M., Zadrozny, S. (eds.) Developments in Fuzzy Sets, Intuitionistic Fuzzy Sets, Generalized Nets and Related Topics. Volume 1: Foundations., pp. 95107. Academic Publishing House EXIT, Warsaw

19.Hinde, C.J., (2009) The statement is contradictory. In: Proceedings of 2009 International Conference on Artificial Intelligence and Soft Computing. pp. 235240. IASTED

20.Hinde, C.J. and Atanassov, K., (2008) On Intuitionistic Fuzzy Negations and Intuitionistic Fuzzy Modal operators with Contradictory Evidence. In: Dimitrov, D., Mladenov, V., Jordanova, S., Mastorakis, N. (eds.) Proceedings of 9th WSEAS International Conference on Fuzzy Systems (FS '08)

21.Hinde, C. and Patching, R., (2007) Inconsistent Intuitionistic Fuzzy Sets. In: Atanassov, K., Bustince, H., Hryniewicz, O., Kacprzyk, J., Krawczak, M., Riecan, B., Szmidt, E. (eds.) Developments in Fuzzy Sets, Intuitionistic Fuzzy Sets, Generalized Nets and Related Topics. Foundations., pp. 155-174. Academic Publishing House EXIT, Warsaw

22.Hinde, C.J,, Patching, R. and McCoy, S., (2007), Inconsistent Intuitionistic Fuzzy Sets and Mass Assignment. In: Atanassov, K., Bustince, H., Hryniewicz, O., Kacprzyk, J., Krawczak, M., Riecan, B., Szmidt, E. (eds.) Developments in Fuzzy Sets, Intuition-istic Fuzzy Sets, Generalized Nets and Related Topics. Foundations., pp. 133-153. Academic Publishing House EXIT, Warsaw

23.Hinde, C.J., Patching, R., Stone, R., Xhemali, D. and McCoy, S. (2007) Reasoning Consistently about Inconsistency. In: Garibaldi, J., Angelov, P. (eds.) Proceedings of 2007 IEEE International Conference on Fuzzy Systems. pp. 769-775

24.Patching, R., Hinde, C.J. and McCoy, S. (2006), Inconsistency and semantic unification. Fuzzy Sets and Systems 157, 2513-2539 (2006)

25.Resconi, G. and Hinde, C.J., (2010) Active sets, fuzzy sets and inconsistency. In: Aranda, J., Xambo, S. (eds.) Proceedings of FUZZIEEE 2010. pp. 354-357. IEEE

26.Resconi, G. and Kovalerchuk, B., (2011), Agents in Quantum and Neural Uncertainty. Medical Information Science Reference (Hershey, New York)

27.Scott, D., (1982), Some ordered sets in computer science. In: Rival, I. (ed.) Ordered Sets, pp. 677-718. Reidel Publishing Company, Boston

28.Xu, Y., Ruan, D., Qin, K., Liu, J., (2003) lattice-valued Logic, Springer

29. Figueira, J. Greco, S., Mousseau, V. and Slowinski. R., (2008) Interactive Multiobjective Optimization using a Set of Additive Value Functions. In J. Branke, K. Deb, K. Miettinen, and R. Slowinski, editors, Multiobjective 
Optimization: Interactive and Evolutionary Approaches, 99--122

30. Greco, S., Mousseau, V. and Slowinski. R. (2008), Ordinal regression revisited: multiple criteria ranking using a set of additive value functions. European Journal of Operational Research, 191(2):415-435, December 2008

31.Blaszczynski, J. Greco, S. and Slowinski, R. (2007) Multi-criteria classification - A new scheme for application of dominance-based decision rules. European Journal of Operational Research, 181(3):1030 - 1044 